\title{
PENSAR ESENCIAL Y LENGUA. HERACLITO Y HEIDEGGER
}

\author{
Juan Iturriaga \\ Universidad de Deusto
}

\section{Proemio experimental}

Para todo traductor le es patente que no puede pretender traducir un texto de una lengua ateniéndose exclusivamente a la estructura gramatical. Es necesario llegar a la comprensión del texto y traspasarlo a términos claros e incluso elegantes (en ello está la calidad de la traducción) de otra lengua.

Naturalmente que se requiere un conocimiento gramatical de ambas lenguas, pero lo más difícil es captar el sentido profundo de lo dicho en una lengua y traducirlo a otra. Lo cual no lleva consigo ninguna traición como dice el manoseado adagio italiano: «tradutore, traditore».

A esas características peculiares a cada lengua le vamos a llamar el «genio de la lengua» ${ }^{1}$. Es indudable que por muy próximas que sean dos lenguas, en su origen y desarrollo como podría ser el catalán, castellano, gallego o portugués, cada una tiene su «genio» propio, que si no se capta, se corre el riesgo de no entender nada del texto propuesto.

Hace ya algún tiempo oí por la radio a un locutor que traducía el título inglés de una canción: "give me a hand». Siguiendo la estructura gramatical rígidamente decía: «dame una mano». De esta forma el inadvertido radioyente entendía, se imaginaba, un saludo habitual de apretón de manos. Pero para alguien con cierto conocimiento del «genio» de la lengua inglesa, no se le escapaba que esa expresión significa en castellano: «ayúdame» o «échame una mano».

Sirva el ejemplo para distinguir entre la gramática y el genio de la lengua.

\footnotetext{
1 Posteriormente en nuestro trabajo lo indentificaremos con los términos alemanes: «anfängliches Denken»y «wesentliches Denken»: pensar original o esencial.
} 


\section{Planteamiento de una paradoja lingüística}

Entrando en nuestro tema no cabe la menor duda, de que hoy día hay muchísima gente que conoce gramaticalmente la lengua vascongada, pero nos preguntamos y nos tememos sobre su comprensión del genio propio de la misma. Se hacen muchos chistes al respecto y no me consta de su veracidad histórica, como la del letrero del ferrocarril que decía: «trenen azpikogonak» («combinaciones de trenes») equivocando una prenda femenina («lo que está debajo del vestido, la saya, la combinación») con un término de ferrocarril («combinaciones de trenes»). Pero el ejemplo quizá por su evidente torpeza resulta demasiado inverosímil.

Sin embargo es cierto que un conocimiento de la gramática no lleva consigo necesariamente una vivencia del genio de la lengua. Cualquiera puede caer en la cuenta de lo que decimos visitando una casa de labranza vascongada de la diferencia entre el lenguaje que usa la abuela de la casa y la nieta. Esta última conoce a la perfección no sólo el lenguaje «unificado» (llamado «batua») sino la manera de expresarse del pueblo y en casa («herriko hitzkuntza»). Pero una vez iniciada la conversación inmediatamente se cae en la cuenta de que la abuela piensa de otro modo, mientras que en la nieta sin que haya ningún error gramatical, la influencia del mundo castellano es mucho más decisivo y por tanto su lenguaje más abierto para un castellano que sabe algo de vascuence.

Mi hipótesis de trabajo es que la abuela posee el genio de la lengua, mientras que la nieta, aunque desde el punto de vista gramatical sea mucho más erudita, con más conocimientos filológicos quizá haya perdido el auténtico genio de la lengua.

No creo que esta hipótesis de trabajo signifique ninguna novedad. Hay innumerables investigadores que van recorriendo lugares donde ancianos conservan el genio de la lengua, porque han tenido muy poco contacto con el modo de pensar castellano, para recoger sus dichos y su manera de expresarse. En el ámbito escrito sucede lo mismo. Se está trabajando mucho en la recogida de versos y textos antiguos ${ }^{2}$, que no han sido tan asediados como lo somos nosotros por un entorno totalmente dominado por la lengua castellana. Difícilmente se encontrará hoy en el País Vasco una persona o lugar en el que no se entienda y hable (aunque sea gramaticalmente incorrecto) el castellano.

2 Un ejemplo laudable de este esfuerzo es la colección «Auspoa», que con tanta competencia y erudición dirige Antonio Zavala Echevarría. 
Para aclarar mi hipótesis de trabajo, permítaseme acudir a un recuerdo personal no muy lejano. Siendo de origen vascongado mis parientes ancianos (cada vez menores en número) me han permitido tener una experiencia singular. Una alumna de la Universidad de Deusto deseaba retirarse a una casa de labranza vascongada («baserri»), sin importarle mucho el estado en que se encontrara, para vivir en independencia y soledad. Debidamente aconsejado acudí a unos parientes míos que se expresan en castellano, pero inmediatamente se cae en la cuenta de que su manera de pensar no pertenece a este lenguaje.

Consciente del genio de la lengua, que entra dentro de la manera de pensar y obrar de la persona, le advertí a mi alumna de Deusto, que cuando fuéramos a tratar de este negocio con mis parientes, que tenían algunas casas de labranza en distintos lugares, algunas de ellas muy abandonadas, no acudiese como lo hacemos hoy día en una inmobiliaria.

Normalmente en una empresa de éstas, se sienta uno en una silla y expone sus deseos. Del otro lado de la mesa directamente se le va respondiendo a cada una de las directrices propuestas y se le señalan alternativas. Al mismo tiempo se le van indicando al presunto cliente precios, situación, ventajas, etc...

De esta manera - le dije yo a mi alumna - no vengas a ver a mis parientes. Ten paciencia. Escucha. Déjales hablar. Hablan castellano pero no piensan en esa lengua.

Efectivamente, nada más iniciado el diálogo y expresado sobriamente nuestro deseo de conseguir una casa de labranza vascongada de la que ellos (mis parientes) pudieran disponer, se cambió todo el tema de la conversación. Nos invitaron a visitar una ermita próxima. Nos enseñaron el altar mayor, indicándonos al señalarnos las paredes de hermosa piedra desnuda, que nuestros antepasados habían contribuido a la mejora y aderezo de la ermita.

Después nos llevaron a los altares laterales y sin ninguna amargura, sencillamente nos transmitieron el dato de que aquellos dos altares habían sido donados por un sacerdote, hermano de su madre, añadiendo que «antes» había unos carteles que lo decía, pero con la renovación de la ermita, los responsables eclesiásticos habían considerado conveniente retirarlos.

Si mi alumna no estuviera prevenida, hubiera interrumpido toda esta conversación para especificar el tema que le había traído a ver a mis parientes. Pero siguiendo mis continuas insinuaciones esperó.

Más tarde nos sentamos a la mesa, sacaron algunos frutos de la tierra, para comer y comenzaron a hablar de «posibilidades» que existían. Insistían una y otra vez mis parientes, que todo ello lo habían recibido 
de sus mayores. Yo me imagino, y no creo que ando lejos de la realidad, que el primer gesto de llevarnos a la ermita, había sido para decirnos dentro del genio de la lengua vascongada, que ellas eran religiosas como sus mayores, generosas como sus mayores, y que daban sin esperar nada en recompensa, aunque luego se olvidaran de ellas, como se habían olvidado de sus mayores bienhechores de la ermita.

Una vez sentados estos principios y habiendo comprobado que la alumna de Deusto sin pestañear los aceptaba todos y se sometía a ellos, poco a poco se fue aclarando el horizonte. Lo primero, se fijaron los términos de un contrato limitado. Mis parientes no querían sentirse implicados en un caso que molestase tanto sus sentimientos religiosos (recordemos la visita a la ermita) ni sus intereses personales. A medida que pasó el tiempo y mis parientes tuvieron certeza de la fidelidad a sus directrices por parte de la alumna de Deusto, le fueron concediendo con increíble generosidad todo. La casa tenía el tejado en muy malas condiciones. Mis parientes se encargaron de arreglarlo y pagarlo. Es verdad que la alumna de Deusto no ahorraba esfuerzos por mejorar el lugar que se le había concedido gratuitamente. Pero mis parientes fueron proporcionándole agua corriente, la luz, cerrar las ventanas, etc...

En una palabra que el genio de la expresión, aunque era castellano, fue típicamente vascongado.

No se trata de un ejemplo paradigmático, porque quizá no todos los vascongados obrarían del mismo modo. Pero no es eso lo que pretendemos decir, sino que este concreto modo de actuar lleva un genio de expresión distinto del corriente castellano.

\section{Introducción en el trasfondo filosófico}

El Licenciado Andrés Poza y Yarza ${ }^{3}$ publicó en Bilbao, en las prensas de Matías Mares, en el año de 1587 un libro titulado: De la antigua lengua, poblaciones y comarcas de las Españas ${ }^{4}$. El libro tiene bastante

3 Andrés Poza y Yarza, Lendoño de Abajo, Torre de Poza, cerca de Orduña, Vizcaya, hacia 1530 - Madrid 18.10.1595.

${ }^{4}$ El volumen se encuentra en la Biblioteca de la Universidad de Deusto. Su signatura topográfica es 936.5 P 85 a. El título completo: De la antigua lengua, poblaciones, y comarcas de las Españas, en que de paso se tocan algunas cosas de la Cantabria. Compuesto por el Licenciado Andrés de Poça, natural de la ciudad de Orduña, y auogado en el muy noble y leal Señorío de Vizcaya. Dirigido a Don Diego de Avendaño y Gamboa, señor de las casas de Vrquiçu, y Olasso, y de la villa de Villa Real y sus valles, y Ballestero mayor del Rey nuestro señor. \& c. Con priuilegio real. Impreso en Bilbao, por Mathias Mares, primer impresor de Vizcaya, 1587. 5h. sin numerart. 70, 36hn. Signat: 5h. sin signatura. 
de polémico apremiado por los ataques de Ocampo 5 y de Ambrosio Morales $^{6}$ cronistas castellanos.

Las afirmaciones del orduñés Poza van muy lejos:

«destas lenguas que se puedan llamar perfectas y elegantes es una la Vascongada» ${ }^{7}$.

Con la fe propia de todo peninsular en el siglo XVI añade:

«ya pudo ser haber querido Dios repartir lenguas según la felicidad del cielo y suelo de la provincia destinada, y que por ello a España repartiese una de las mejores» ${ }^{8}$.

Obsérvese que no contrapone Poza: España al vascuence, sino que lo incluye en ella.

Pero para llegar al centro de nuestra reflexión vamos a transcribir un texto un tanto largo:

«Veamos ahora del sol la más ilustre criatura de los visible, y hallaremos que sólo en el vascuence se muestra su propiedad encarecida, con un énfasis muy conpendioso, Eguzguia, Egusgueya, significa: mirad, atended el principio, fundamento, obra, llamamiento, o principio del día. Porque todo esto apuntan estas breves y substanciales sílabas del vocablo Eguzgueia. Que aunque el sol el latín, castellano, italiano y francés está bien encarecido en la excelencia de su soledad, sin par ni igual, todavia en vascuence se muestra su etimología más filosófica y substancial, porque el latino con sus lenguas dependientes todas solo muestra lo que todos ven y saben, que no hay otro sol, y que el es solo, pero el vascongado entra con atención de su admirable compostura y enseña que es fuente de la luz y claridad deste universo.» ${ }^{9}$

B-T4 B-I4 K2. En la portada grabado en madera con el escudo de la familia Poza, en $8^{\circ}$ $(21 \mathrm{~cm})$. El rey al que alude el título es Felipe II, rey de España. Valladolid 21.5.1527 - El Escorial 13.9.1598. Rey también de Portugal a partir de 1587. Lo citaremos en adelante: De la antigua lengua ...

5 OCAMPO, Florián de: Los cinco primeros libros de Crónica general de Expaña. Medina del Campo, Guillermo de Millis, 1553. Ocampo vivió desde aproximadamente 1499 a 1558. Este volumen se encuentra en la Biblioteca del Santuario de Loyola. Signatura topográfica [A II 446].

${ }^{6}$ Morales, Ambrosio: Los cinco libros postreros de la coronica general de España. Córdoba, Gabriel Ramos Bejarano, impresor; Francisco Roberte, editor, 1586. Este volumen se encuentra en la Biblioteca del Santuario de Loyola, signatura topográfica [A II 238]. Ambrosio Morales nació en Córdoba a finales de 1513 y murió en la misma ciudad el 21.9.1591.

7 Andrés Poza: De la antigua lengua ... pp. 33v y 34r. Signatura K1v y K2r.

8 Andrés PozA: De la antigua lengua ... pp. 33r y 34r. Signatura K1r y K2v.

9 Andrés PozA: De la antigua lengua ... pp. 33v y 34r, signatura K1v y K2r. 
Sin entrar en la coherencia y seguridad de la etimología, quiero señalar cómo Poza apunta al genio de la lengua, que él llama con notable precisión «más filosófica y substancial».

Pero el párrafo citado no queremos que sea otra cosa sino una introducción a otra afirmación más seria del licenciado Andrés Poza:

«Por los cuales pocos ejemplos ... ya las naciones españolas, podrán reconocer la elegancia de su lengua primera ... que en la Cantabria se ha conservado, y hoy día permanece, es fundada en una muy profunda filosofía de sentidos substanciales, y que la que esto tiene no es ni puede ser bárbara, como algunos la baptizan, no más porque no la saben, ni la entienden.» ${ }^{10}$

Hemos puesto de relieve conscientemente los dos pilares que queremos hacer resaltar cuando hablamos de la pureza de la lengua vascongada. Poza sostiene que la soporta una profunda filosofía y un sentido substancial. Por otro lado apunta para quienes no quieren reconocer este hecho que simplemente no la saben ni la entienden.

Ahora vamos a dar un salto bastante considerable. El filósofo existencialista Martin Heidegger escribió un estudio sobre Heráclito, filósofo griego del siglo v a.C. a quien él llama fundamental, original (de origen) de la filosofía científica occidental ${ }^{11}$.

Se trata de unas clases magistrales (seminarios), que dio entre los años 1923-1944. Su pretensión es buscar las fuentes del pensamiento occidental. Llega a decir:

«la filosofía en su esencia es tan originariamente occidental, que lleva en sí el fundamento de la historia de Occidente ... la técnica no es sino una consecuencia de la filosofía y nada más» ${ }^{12}$.

Heidegger como pensador tiene la intención de encontrar las bases de la cultura occidental, cuyo cogollo es la filosofía, de donde nace la técnica y la historia de Occidente. Naturalmente este fundamento o primera piedra de Occidente nació en Grecia. Es un hecho. No nos preguntemos ni el cómo ni el por qué. El mismo Immanuel Kant, en su Lógica afirma rotundamente:

«cuándo y cómo brotó en primer lugar entre los griegos el espíritu filosófico, no lo podemos determinar» ${ }^{13}$.

\footnotetext{
10 P. 35, signatura K3r, el subrayado es nuestro.

11 Este estudio se encuentra en el vol. 55. Gesamtausgabe, Frankfurt am Main, Vittorio Klostermann, 1979. Lo citaremos: Obras completas, t. 55.

12 Martin Heidegger: Obras completas, t. 55, p 3. La traducción es nuestra.

13 Martin Heidegger: Obras completas, t. 55, p. 4. Cita: Immanuel Kant, Logik, Gesamtausgabe. Ed. E. Cassirer, 10 vols. + 1 Erläuterungs-Band, t. 8, p. 346. La traducción es nuestra.
} 
Vamos a buscar con Heidegger los cimientos, el principio, lo más arcaico de nuestro Occidente.

No es sólo preocupación de Heidegger la que acabamos de exponer, sino que filósofos como Hegel, Nietzsche y poetas como Hörderlin y Goethe escarbaron en Heráclito como uno de los representantes genuinos del pensar primitivo, arcaico, original. Hasta tal punto que Hördelin citando a Goethe dice: «el placer y el amor son las alas para las grandes empresas» ${ }^{14}$.

No piense el lector que nos ha seguido hasta aquí, que desvariamos. Estamos girando en espiral para llegar al fondo de nuestro tema, que creemos fundamental para Occidente. Heidegger nos ha hablado de filosofía original y arcaica, Hörderlin nos ha señalado el fundamento de nuestra reflexión: «el placer y el amor» como los motores de toda la civilización occidental.

Nuestra tarea es entender y traducir el pensamiento original y primitivo de los griegos, en concreto de Heráclito.

\section{Las dificultades del pensamiento occidental}

El primer paso que debemos dar es la traducción de esa filosofía arcaica y fundamental. Pero toda traducción, tomada en sí misma lleva consigo una interpretación. La interpretación y la traducción son lo mismo.

Para aligerar nuestras deducciones, tomemos por ejemplo el filósofo Immanuel Kant en su obra Crítica de la razón pura. Para entenderla hay que irla traduciendo, al menos mentalmente, cada uno a sus propios esquemas. En este caso se puede llegar a la conclusión de que el traductor ha entendido al pensador mejor que el mismo pensador o filósofo. Heidegger afirma que esto puede suceder, sin que ello signifique un desprestigio del autor ${ }^{15}$.

Aquí nos separamos de Heidegger. Es cierto que lo que dice un pensador, puede expresarlo otro con más claridad o precisión, pero ya no es lo que dice el pensador original, es otra cosa. Si es mejor o peor, lo puede decir cualquier filósofo según su manera de pensar. Como cuando en nuestros días se desprecia inconscientemente la filosofía llamada escolástica o neoescolástica, para dejar paso a una hermenéutica

14 Martin HeIDEgGeR: Obras completas, t. 55, p. 30. El texto alemán: «Lust und Liebe sind die Fittige zu groBen Thaten». La traducción es nuestra. La cita está tomada según Heidegger de Friedrich Hördelin: Gesamtausgabe. Ed. Hellingrath, t. 6, p. 232.

15 Martin HeIDEGGER: Obras completas, t. 55, p. 63. 
o a un pensamiento postmoderno, que incluso se llega a suavizar con el anglicismo «light» postmodernidad. Según los distintos puntos de vista se juzga el pensar original, pero jamás estos juicios críticos sean favorables, insultantes, más claros o más oscuros pueden substituir el pensamiento original.

En este momento creemos que podemos volver a Poza y al idioma vascongado. Contiene esta lengua un pensar primitivo, arcaico, original (no en el sentido de singular sino de carencia de procedencia conocida). Por tanto, la lengua en sí misma lleva el sello de una filosofía profunda y substancial.

Poza y Heidegger desde dos ópticas distintas, muy separadas en el tiempo y en la cultura, sacan la misma conclusión. Este pensar original, primitivo, excita el desprecio de mucha gente porque no lo entienden. Al no poder comprender, lo sienten como un insulto. Quizá no por ese motivo, pero es también consecuencia de esta incomprensión por parte de muchos el rotular al pensador o a la lengua (en el caso del genio de la vascongada) de «poco clara», «difícil», «misteriosa» ${ }^{16}$.

Es obvio que la lengua no la podemos considerar antropomórficamente como un filósofo, pero tras la lengua está el «ser» de unas gentes, que piensan y hablan en ese lenguaje. Diríamos con los filósofos de un modo tradicional que en primer lugar (in actu primo) se encuentra la manera de ser propia de un pueblo y como consecuencia surge una lengua que la expresa (in actu secundo). Pero si no se tiene ese genio, esa manera de «ser» y «existir» de esas gentes, nunca entenderemos su lengua y siempre andaremos «traduciendo»e «interpretando».

No podemos evitar caer en la tentación de recordar, por lo oportuna que consideramos una digresión que en este lugar hace Heidegger con una valoración del filósofo Schopenhauer. No queremos decir que tenga razón en la evaluación de este pensador, ni siquiera nos atrevemos a suscribir personalmente un juicio de tal calidad.

Dice Heidegger que Schopenhauer por su dependencia de Nietzsche por un lado y por otro en razón de sus diatribas contra Schelling y Hegel declarándolos «oscuros» demuestra que no es ningún pensador o filósofo. Con ello Heidegger nos induce a pensar que hay que ser muy cautos, al evaluar lo que no entendemos como «oscuro» y mucho menos dar al término un sentido negativo, porque nos descalificamos a nosotros mismos como pensadores. Llegamos así al ciudadano orduñés, que señala como invectiva vacía el título de «bárbara» dado a la lengua

16 Martin HeIDEgGer: Obras completas, t. 55, p. 20. 
vascongada, por la sencilla razón de que no se entiende su genio. «Nunca es el mérito de quien intenta interpretar o entender mejor algo primitivo y arcaico, sino que es un don de quien es interpretado.» ${ }^{17}$

Todavía tenemos que seguir la espiral del pensamiento primitivo y fundamental para desentrañar el sentido de una lengua primitiva y arcaica.

\section{Las dos maneras de «pensar» que diferencia Heidegger}

Distingue Heidegger entre dos filosofías, o dos maneras de pensar. Una es la lógica y coherencia (mayor o menor) que guardamos en nuestro quehacer cotidiano. Otra distinta es la del pensador que contempla el mundo como «abierto a su pensamiento». De esta manera este segundo personaje se convierte en un pensador esencial, científico, sistemático. El paso de un tipo de filosofía a la otra está separado por un abismo $^{18}$.

Es curiosa la coincidencia incluso terminológica entre Heidegger y Poza. Al tipo de filosofía que ha descrito en segundo lugar la llama simplemente «filosofía esencial» (wesentliches Denkes) que sin duda se identifica con las palabras de Poza: la lengua vascongada es «filosófica y substancial».

Cuando nos movemos dentro de la filosofía cotidiana («gewöhnliches Denken») encontramos el otro tipo arcaico, original, substancial de filosofía como ilógico, ¿para qué meterse en grandes elucubraciones, cuando tenemos la lógica del quehacer ordinario? No tiene sentido. Heidegger se pregunta desde esa filosofía de cada día:

«¿cómo llegamos a manejar la historia y absolutamente el comienzo de la significación esencial de nuestra historia? ¿es que podemos ni siquiera pretender abarcar esa historia?» ${ }^{19}$.

Esto es lo que se pregunta el hombre de la calle: ¿para qué nos vamos a complicar la vida con cuestiones oscuras, espinosas y difíciles? ¿por qué no nos conformamos con decir las cosas «lo más simple posible» de forma que lo esencial se ciña al hombre y no al revés que el hombre dependa de esa oscura esencia (Poza diría substancia)? Y si queremos descender más en el vilipendio de esta actitud, diremos esa frase que tanto repetimos cuando no entendemos algo: «Oiga Vd., a mí hábleme Vd. en cristiano».

\footnotetext{
17 Martin HeidegGer: Obras completas, t. 55, p. 64.

18 Martin HeIdegGer: Obras completas, t. 55, p. 120.

19 Martin Heidegger: Obras completas, t. 55, p. 122.
} 
Todas estas consideraciones las hace Heidegger en torno a uno de los fragmentos que se conservan de Heráclito. Nosotros vamos a dejar al lado por el momento la interpretación de ese texto griego, para tratar de entender las conclusiones a las que llega.

\section{Respuesta de Heidegger a la dicotomía de filosofías}

Siendo Heidegger un filósofo de mucha mayor potencia y rigor científico que Andrés Poza, sin embargo no deja de llamar la atención la curiosa coincidencia de pensamiento. Del Heráclito griego Heidegger se vuelve a sus compatriotas alemanes y les dice:

«solamente se puede dar por sentado que los alemanes busquen "lo alemán" y llegan de este modo a la auténtica comprensión de la historia del mundo. Lo cual no es una presunción, sino la conciencia de la necesidad de una decisión sobre lo inicial necesario. Tenemos que aprender a pensar por encima de la fugacidad efímera de los días pasajeros, de lo ordinario en lo que "es" el pensar en eso necesario y experimentar absolutamente una única significación $»^{20}$.

Las palabras de Heidegger van dirigidas a los alemanes, ¡ojalá, que los vascos, siguiendo a Poza, nos las aplicáramos! Podemos seguir preocupándonos de nuestras carreteras y ferrocarriles, nuestros museos, nuestros presos y muertos violentos, picardía cotidiana organizada, etc. ... pero eso es pensar ordinario, cotidiano, pasajero, efímero. Está bien. Pero como plásticamente expresa un buen amigo es como entrar en una violenta discusión sobre si se ha dado la exacta nota en el chistu, cuando la embarcación se está hundiendo. Heidegger les dice a los alemanes y Poza, a vascos y castellanos: vamos a pensar sobre lo que «somos», nuestro Ser, eso que es «necesario» y que tenemos que experimentar en la comprensión de nuestra historia. Entendiendo historia no en el sentido estricto de la ciencia histórica, sino del desarrollo y actualidad del genio de una lengua y por tanto de un pueblo.

\section{Interpretaciones de la solución presentada por Heidegger}

En este momento nuevos horizontes se nos abren al pensamiento. Hemos leído parcialmente un par de artículos de S.L. Bartky de la Universidad de Illinois, en la revista Philosophy and Phenomenological

20 Martin HeIDEgGER: Obras completas, t. 55, p. 125. 
Research. Como consecuencia de estas lecturas me parece apropiado añadir algunas reflexiones al pensamiento arcaico y original de Andrés Poza sobre el vascuence como lengua filosófica y substancial en referencia a lo expresado por Heidegger al tratar de interpretar a Heráclito.

Martin Heidegger estudia a Heráclito en una obra suya en dos secciones, de las cuales tiene una primera parte ${ }^{21}$, que sin ningún prejuicio filosófico traduciríamos simplemente: «El comienzo del pensamiento occidental». En seguida caemos en la cuenta de que no es la pretensión de Heidegger hacer una historia de cómo se origina el pensamiento en Occidente. La primera pregunta es obvia, rayando con la estupidez ¿qué pensamiento? El hombre siempre ha pensado, es una característica de la condición humana. A simple vista la pregunta tiene todos los visos de ser completamente estéril e inútil. Desde que el hombre es racional, piensa. En Oriente y en Occidente, en cualquier parte del mundo.

Naturalmente Heidegger no va por ese camino, sino que cita a $\mathrm{He}-$ ráclito de quien habla Diógenes Laercio ${ }^{22}$ que se refiere una frase de Heráclito:

«¿qué admiráis, oh estúpidos?» Heidegger se pregunta: «¿os admiráis de que un pensador, lejos del ámbito del comercio y del éxito, jugando inútilmente pasa el tiempo y ni siquiera sigue el hilo de sus pensamientos, que es lo que menos importa, sino que ni consigue lo que se debe exigir a un pensador? ... ¿qué cosa verdaderamente admirable se esconde en el actuar inofensivo del pensador? $\gg^{23}$

Diógenes Laercio (Heráclito) interpretado por Heidegger descubre la actitud sociológica de la gente ante el inútil juego e inofensiva ocupación del pensador.

Añade Heidegger otro detalle importante. Piensa que:

«nos haríamos una idea ridícula del pensador, si creyéramos que siempre está libre de error. Porque los pensadores esenciales son por eso mismo los que a pesar de los muchos errores, que les suceden, piensan lo verdadero. De ahí la diferencia entre el pensador y otros tipos de gente, otros aspectos filosóficos como la crítica y la polémica, que son necesarias y usuales en el interior de las ciencias» ${ }^{24}$.

21 Martin HeidegGer: Obras completas t. 55 pp. 1-184.

22 Diógenes Laercio, IX, 3.

23 Martin Heidegger: Obras completas, t. 55, p. 10.

${ }^{24}$ Martin HeIDEgGer: Obras completas, t. 55, p. 41. 
Pero no nos apresuremos, Heidegger «el mal fundamental en el pensar esencial es la prisa» ${ }^{25}$. Seguiremos llanamente la intuición de Poza, con la ayuda de Heráclito y de Heidegger.

Estudiando a Heráclito, Heidegger se enfrenta con sus «palabras», con «su lenguaje». En este momento llega a la siguiente conclusión:

«puesto que hasta ahora nos hemos ocupado de la palabra incluso en cuanto a su esencia, solamente externamente, no sabemos de ningún otro camino que la gramática, que nos debe bastar en este obstáculo del itinerario» $^{26}$.

Caemos sin gran esfuerzo en la cuenta de que Heidegger no está satisfecho con este primer paso para obviar una dificultad que se presenta en su andadura.

\section{La función de la gramática en el «pensar»}

La gramática es una gran ayuda para desde fuera entrar en el pensamiento de un lenguaje. Sin embargo, nunca podemos olvidar, que la gramática no precede al lenguaje, sino al revés. Los gramáticos hemos trabajado con los textos ya existentes. Los pensadores se han expresado en escritos, que en el caso de Heráclito son fragmentos. De ahí que los gramáticos hemos deducido unas reglas para aplicarlas a otras instancias. Ya se ve que este sentido instrumental y técnico de la gramática no puede satisfacer al pensador esencial cuando lee un texto.

Volviendo a la lengua vascongada queremos corroborar lo dicho con un ejemplo convincente. Agustín Cardaberaz ${ }^{27}$, un jesuita residente en el Santuario de Loyola, la mayor parte de su vida religiosa activa dedicado a misionero itinerante, predicaba indistintamente en castellano y en vascuence. Al ser nacido en Hernani, su dialecto propio era guipuzcoano, pero teniendo que recorrer también enclaves de población con el dialecto vizcaíno ${ }^{28}$. En uno de ellos dice textualmente:

«El vizcaíno obra muchas veces a su modo y también según el de aquí [Guipúzcoa]. No hay que creer a los vagos sin cabeza, éstos no aprecian el conocer las cosas del cielo y sin temor de Dios para quitar

25 Martin HeIDEGGER: Obras completas, t. 55, p. 62.

26 Martin HeIDEGGER: Obras completas, t. 55, p. 71.

27 Hernani, Guipúzcoa 28.12.1703 - Castel S. Giovanni, Bolonia 18.10.1770.

28 Debemos el hallazgo y posibilidad de lectura de estos raros documentos en vascuence a la amabilidad del Archivero del Archivo Histórico de Loyola, P. José Ramón Eguillor S.J. 
los buenos ánimos a los cristianos, dicen en contra del vascuence cuanto se les ocurre: y lo que los niños leen fácilmente, con vergüenza o sin ella, no quieren aprender ni saber. S. Agustín dice en una ocasión: nos da vergüenza seguir al bueno; y no tememos de no seguirle. Que el Señor les convierta o les dé un escarmiento. Amén.» ${ }^{29}$

Del texto se deduce que el piadoso Cardaberaz aunque predicaba para vizcaínos, su lengua no era así de acuerdo con las reglas de la gramática utilizada en Vizcaya. El texto está escrito totalmente en dialecto guipuzcoano ${ }^{30}$. Pero lo que resulta más importante es que ya en el s. XVIII un conocedor del vascuence señala el desprecio que suscita entre algunos, según él, no por aversión a la lengua, sino a la característica propia en aquellos tiempos de las gentes de habla vascongada con relación a la religión. De esta manera con el desprestigio de la lengua se apartan de las cosas más sencillas que incluso los niños no encuentran ninguna dificultad.

Así pues, si la gramática con sus normativas no basta ni satisface al pensador esencial, ¿qué nos queda por hacer?, ¿cómo podemos estar tranquilos en nuestro pensar, germinal, original, fundamental?

Heidegger nos ofrece un anclaje para seguir adelante en nuestra reflexión sobre la lengua y la palabra ${ }^{31}$. Según la tradición occidental es característica de la esencia del hombre el poder hablar (los griegos decían: logon echon). En cuanto sabemos sólo tenemos los hombres esta propiedad: la palabra, enfrentarse con el saber y con todo lo que se presenta con la palabra, aunque no podamos expresarlo todo. Precisamente este acontecer de que lo que aparece del pensar proviene de las palabras, es la única razón para que nos encontremos con lo inexpresable. Cualquier estatua hermosa, cualquier templo, toda música de flauta es nada si no se hallara como en su casa en la esfera de la palabra.

29 El texto original reza así:

«Bizcaitar asco beren modura, ta emengora eguin dira. Nagui alper burugabeai ez siñistu: oiec ceruco gauzac jaquiteco gogoric eztute, ta Jaincoaren bildurgabe Cristau onai gogoa quentzeco, gogoac ematen dien gucia Eusqueraren contra esaten dute: eta aurrac erraz iracurten dutena, lotsaz, edo lotsa gabe, icasi ta jaquin nai estute. S. Agustinec onelaco batean ciona: onai jarraitzeaz lotsa guera; eta onai ez jarraitzea lotza ezquera. Onelacoai Jaincoac centsua diela, edo erremedia ditzala. Amen.» Archivo Histórico de Loyola. Fondo de Cardaberaz. Sermón manuscrito de la propia mano del autor. La traducción castellana y el subrayado es nuestro.

30 Para esta afirmación, como para la corrección de la traducción, del texto de Cardaberaz que acabamos de aducir, hemos tenido el consejo y la ayuda del Prof. Gotzon Gárate de la Universidad de Deusto.

31 Martin HeIDEGGER: Obras completas, t. 55, p. 82. 


\section{El Ser y la palabra}

En este momento Heidegger se vuelve muy negativo. Razona del siguiente modo. Si tenemos una disposición, para el ejercicio de la cual solamente es necesaria la decisión para lo sencillo, no buscar un sentido recóndito, ni una sabiduría singular sino sólo esto:

«que el hombre, que según su esencia "tiene la palabra", "ha perdido" precisamente la palabra de todas las palabras, en cuanto rechace insensatamente como la nada más absoluta de todas las nadas la palabra "ser", sin embargo no la rechaza totalmente, porque es evidente que no la puede excluir sin perder su propia esencia» ${ }^{32}$.

Es esta una interpretación magistral de lo que significa para el hombre la palabra y su conexión necesaria con el ser. Podemos ignorar el ser como la nada más despreciable de todas las nadas, pero es evidente que tal cosa no la podemos hacer, porque nos despojamos de nuestro propio ser. Por eso, según entendemos a Heidegger, cuando el hombre habla, tiene la palabra, ésta nace de su ser. No hay manera de escaparse de este funcionamiento, porque el hablar, el usar la palabra es propio de la esencia del hombre. No se puede el hombre vaciar de su esencia. De ahí que el ser le conduzca al hombre dotado de palabra a lo inexpresable, cuando intente reducir a palabra el ser que es inefable.

De lo dicho concluimos que aquí está el núcleo, la raíz, la fuente, el fuego, la armonía, el juego inútil, de todo el pensar occidental, no en un sentido vulgar, sino esencial, original, seminal, originario.

Bartky estudia en el artículo que hemos citado antes los diversos sentidos de expresiones tan frecuentes en Heidegger como «anfängliches Denken», «wesentliches Denken».

Estas expresiones en lengua alemana tienen en Heidegger su sentido peculiar. En primer lugar lo distingue del «gewöhnliches Denken», «pensamiento ordinario», «pensamiento cotidiano» ${ }^{33}$, que sigue el curso de nuestras representaciones mentales corrientes, de cada día. Pero este modo de pensar nos lleva indefectiblemente a paradojas insolubles. Siendo la forma de pensar más ordinaria se convierte en la más complicada porque no penetra en el misterio de las palabras, se queda sólo en la superficie. De esta forma encuentra la filosofía como paradójica, el «pensar» como esfuerzo inútil.

Heidegger nos pone un ejemplo que quizá pueda ayudarnos a la comprensión de estas dos formas de pensar. Cuando leemos los frag-

32 Martin HeidegGer: Obras completas, t. 55, p. 83.
33 Martin HeidegGer: Obras completas, t. 55, p. 52. 
mentos de Heráclito no lo tenemos como el «creador» de una filosofía, sino «fuego» o como «juego» ${ }^{34}$. Para aclarar lo que quiere decir aduce dos historias de la vida de Heráclito.

1. «Se cuenta de Heráclito lo que dijo a unos extranjeros que deseaban encontrarle. Cuando se le acercaron le vieron calentándose junto a un horno de pan y se quedaron plantados. Viéndoles sorprendidos les animó a acercarse con la frase: "también aquí están presentes los dioses ...".»35

2. «Se retiró [Heráclito] al templo de Artemisa (Diana en la mitología latina) para jugar con los niños a las tabas. Le rodeaban los Efesios (sus compatriotas), y les dijo: “¿qué os admiráis, estúpidos? ¿no es mejor hacer esto que con vosotros hacer política (polis = ciudad)?"» ${ }^{36}$

En ambos casos la presencia del pensador junto al horno de pan o en el templo se muestra como lo contrario de lo que se esperaba. En el horno de pan se encuentran todos decepcionados, en el templo sorprendidos. No aparece nada del arte y esencia del pensador.

Concluye Heidegger:

«en el futuro caeremos en la cuenta si y hasta qué punto Heráclito como pensador habla "esencialmente" de "fuego" y de "juego", si y hasta qué punto con el "fuego" y el "juego" trata "algo esencial", que al mismo tiempo indica la presencia de los dioses $»^{37}$.

De esta forma poco a poco llegamos a la comprensión de lo que quisiéramos encontrar en el sustrato de oscuridad de la utilización de las palabras todavía imprecisas de un lenguaje antiguo y «primitivo» de los antiguos pensadores no quiere decir falta de educación o de cultivo sino lo primario de lo «originario» (anfängliches Denken) y de su sencillez en él y sólo en é ${ }^{38}$.

\section{Una explicación del «pensar esencial»}

S.L. Bartky de la Universidad de Illinois se ocupa del sentido de este pensar esencial, primitivo en un artículo ${ }^{39}$.

34 Martin HeidegGer: Obras completas, t. 55, p. 24.

35 Aristóteles, de part. anim. A5. 645 a 17. La traducción del griego es nuestra.

36 Diógenes LAERCIO, IX, 3. La traducción del griego es nuestra.

37 Martin HeIDEgGer: Obras completas, t. 55, p. 24.

38 Martin HeIDEgGer: Obras completas, t. 55, p. 27.

39 S.L. BARTKY: «Originative Thinking in the later philosophy of Heidegger». En: Philosophy and Phenomenological Research, t. 30, 1969-1970, pp. 368-381. 
En primer lugar independientemente de lo que veamos en Bartky, Heidegger no entiende el pensar esencial y primitivo simplemente como algo abstracto sino de acuerdo con el título que da a esta primera parte del tomo 55 de sus obras completas, «El comienzo del pensar occidental» está representado por tres filósofos: Anaximandro, Parménides y Heráclito 40 .

Bartky se debate en inglés para traducir lo que Heidegger llama el pensar «nuevo» («the new thought» ${ }^{41}$, naturalmente no en el sentido temporal). Los dos términos que utiliza Heidegger son en alemán: «anfängliches Denken» y «wesentliches Denken». El erudito de la Universidad de Illinois traduce como «pensar originario» («originative thinking»), «pensar esencial» («essential thinking»).

El Prof. Jaime Echarri de la Universidad de Deusto en una obra póstuma que aparecerá pronto, como esperamos, traduce el inglés «originative» por «originativo». Pero este término es un neologismo, que siempre puede ser discutido. Esta es la diferencia que existe en términos de normativa entre países y lenguas como el inglés (tanto del Reino Unido, como de Estados Unidos), del alemán y de otras lenguas con respecto al castellano y al español. Lo mismo que en Francia, en el Estado español existe la Real Academia de la Lengua. Este supremo organismo tiene la facultad de decidir lo que es correcto e incorrecto con su diccionario ${ }^{42}$. El resultado de esta larga digresión es que Bartky puede utilizar una palabra como «originative» que ignora el famoso The Concise Oxford Dictionary of Current English ${ }^{43}$. Pero nadie le puede reprochar nada porque no existe en inglés ningún órgano autoritativo que pueda determinar la corrección o propiedad de un término lingüístico. De esta libertad no gozamos los que nos expresamos en castellano.

Por esta razón otros comentadores de Heidegger traducen al inglés las palabras de Heidegger como «pensar primario» («primal»), «seminal» («seminal»), o — dice Bartky— «más recientemente "fundacional" ${ }^{44}$. De ahí que concluya Heidegger:

«El lenguaje del pensador seminal (primario, fundacional) tiene la nobleza de lo seminal. La palabra está al inicio del pensar.» ${ }^{45}$

\footnotetext{
Martin HeIDEGGer: Obras completas, t. 55, p. 22.

Originative Thinking ... p. 368.

Ultima edición 1992.

43 Oxford, Clarendon Press, 1969.

44 Así William J. Richardson, S.J., Heidegger, through Phenomenology to Thought. La Haya, 1963, p. 16 y passim.

45 Obras completas, t. 55, p. 27.
} 
Porque la palabra seminal está en la base del pensar, un lenguaje como el vasco que es fundacional, primario, originario constituye la base del pensar esencial, arcaico ${ }^{46}$. Este género de lenguaje descubre el misterio, el secreto de la apertura del propio ser y de su ocultamiento. Dualidad que es la «diferencia ontológica» entre el ser (Sein) y los seres (Seiendes).

\section{Conclusiones}

1. No necesariamente quien conoce y domina bien la sintaxis y gramática del vascuence, ha captado el genio de la lengua y consecuentemente del pueblo vasco.

2. Naturalmente el que conoce a la perfección la estructura gramatical de la lengua está más cerca y tiene una plataforma más adecuada desde el punto de vista filológico para llegar a ese «único necesario», «el pensar esencial, arcaico, original» propio de una lengua que según Poza es «filosófica y substancial».

3. Quien se haga la pregunta sobre la utilidad de tal esfuerzo mental y sobre todo humano (de todo el hombre) está en el nivel del pensar y la filosofía cotidiana, efímera, jamás salvará el abismo que le separa de lo «esencial, fundamental, orginario, arcaico».

4. Por nuestra parte, como opinión meramente personal, estamos convencidos de que el genio de la lengua vascongada y por tanto el del pueblo que la creó va a desaparecer completamente en pocos decenios. No se trata de genocidio, ni de exigir responsabilidades, es una decisión de la historia. Se puede afirmar sin temor a equivocarse que el genio de la lengua vasca y de su pueblo va desapareciendo. Con ello no queremos hacer ninguna previsión sobre los tantos por ciento que hablan actualmente o en un futuro próximo la lengua vascongada.

Para suavizar un poco la amargura de las precedentes conclusiones aduciré dos sencillos ejemplos. El primero se refiere al pueblo judío. No hay ninguna duda de que la lengua y el talante del pueblo judío actualmente dista abismalmente del que se refleja en el texto masorético de la Biblia. Se habla hebreo, se siente la unidad judía, pero no es «el pensar arcaico, original, fundamental», que le constituía al pueblo judío como tal en la lectura de lo que llamamos Antiguo Testamento en la Biblia.

46 No solamente en el sentido del Diccionario de la Real Academia: «muy antiguo», sino en el sentido etimológico del griego archê, «mandato», «dominio», «normativo». 
La segunda imagen consoladora que quisiéramos ofrecer es volver a la historia con la que hemos inciado este trabajo. La alumna de Deusto que tiene su casa de labranza vasca arreglada hasta cierto punto, no conoce ni siquiera gramaticalmente la lengua vascongada, en cuyo genio piensan y viven mis parientes donantes generosos de la casa. Pero consuela saber que esta alumna de Deusto acierta siempre en su traducción espiritual al castellano de esa mentalidad o genio del pueblo vascongado. Apenas necesitan palabras entre mis parientes y ella. Se trata siempre de una traducción, de una interpretación, pero al menos en este caso ha comprendido (sin saber la gramática) el genio de la lengua y del pueblo vasco.

Con cierta añoranza de años de infancia mezclada con una ligera amargura ante un oscuro futuro, quiero concluir estas líneas con la traducción castellana de unos versos del navarro vasco-francés Bernard Etxepare (1545) en la primera impresión de un libro en lengua vascongada:

\author{
Entre las lenguas gozabas \\ de poca reputación; \\ pero ahora vas a tener \\ gran honor entre todas.
}

¡Euskara, camina por todo el mundo!47

47 EtXePARE, Bernard: Linguae uascorum primitiae. Bilbao, Real Academia de la Lengua Vasca, 1995, p. 173, verso 14. En el texto original:

Lengoajetan ohi inzan

estimatze gutitan;

orai aldiz hik behar duk

ohoria orotan.

Heuskara,

habil mundu guzira. 